ments-it being quite unnecessary to add more of the solution to bring about the required result-I would observe that this agent would be more effective than it is commonly found to be if it were previously mixed with water, and then used when well shaken up, after the manner of other liquid disinfectants, instead of being rudely thrown about in the dry state, or mixed up with a little water in a saucer. In these experiments it was found that a solution containing 140 grains of Chloride of Lime to the gallon was strong enough to disinfect a fluid such as that used in the experiments above detailed.

ART. VIII.-A Spectroscopic Explanation of the Action of Nitrous Oxide. By Charles A. MacMunn, B.A., M.D. Dubl., Wolverhampton.

THe spectroscope enables us to confirm the conclusion which is now generally accepted, that nitrous oxide produces its anæsthetic effects by stopping the supply of oxygen to the blood. ${ }^{a}$ Hæmoglobin exists in two states-oxidised hæmoglobin, the spectrum of which consists of two bands, and deoxidised hæmoglobin, the spectrum of which consists of one band. The deoxidised form can be produced artificially by adding certain substances to blood which have a greater affinity for oxygen than hæmoglobin has--such as an ammoniacal solution of ferrous sulphate, to which enough tartaric acid has been added to prevent precipitation by alkalies, or sulphide of ammonium; indifferent gases also reduce hæmoglobin; so also does the vacuum produced by the air-pump. I myself discovered-though unfortunately anticipated by Koselanski-that venous blood in the body becomes spontaneously reduced after death-evidently an effect of decomposition, since the same thing takes place in blood out of the body when decomposition has begun to set in; but venous blood in the living body gives the two-banded spectrum of oxyhæmoglobin-a fact easily proved; for, if we focus a vein in a frog's web with a high-power objective, then, having thrown it slightly out of focus, substitute the spectrum eyepiece for the ordinary eyepiece of the microscope, we do not get the spectrum of reduced, but that of oxidised, hæmoglobin, because venous blood always contains a certain amount of oxygen. Nor does venous blood, much less arterial, give this band immediately after death; a certain time is necessary for the reduction of the hæmoglobin.

* Wood's Therapeutics. 1876. P. 268. 
But in death from poisoning by nitrous oxide the venous and arterial blood all over the body gives the one-banded spectrum of reduced homoglobin, immediately after death, provided the examination of the blood is conducted properly-viz., in the manner I described in The British Medical Journal, Feb. 1, 1879-by putting the blood on a glass-slip and at once covering it with a microscopic cover-glass, and then examining with the Sorby-Browning microspectroscope. A Guinea-pig was given nitrous oxide from a dentist's gas-bag until it ceased to exist, and the blood was examined without loss of time. From the right auricle, right ventricle, left auricle and left ventricle, portal and hepatic veins, splenic vein, supra-orbital veins, aorta and muscles, the blood, on being examined, gave the onebanded spectrum of reduced homoglobin. The right ventricle was firmly contracted and empty; the liver was darker in colour than normal; the cerebral sinuses and cerebral blood-vessels generally were full of dark-coloured blood, which gave the band mentioned above. On exposure to air the spectrum changed to that of oxyhæmoglobin, which was capable of being reduced-showing plainly that the nitrous oxide had not entered into a combination with the hæmoglobin, such as carbonic oxide and nitrous oxide form with it, for reducing agents fail to displace these gases from their combinations with hrmoglobin. I do not wish it to be understood that I am ignorant of the fact that nitrous oxide reduces hæmoglobin in solution, as this is known to readers of modern text-books of physiology; but, so far as I know, no one has examined the blood (of an animal poisoned with this gas) in the manner which $I$ have described, which is the only method not liable to fallacy, and which has already led to some important results.

\section{SPICE-BAG POULTICE.}

WARM applications over the abdomen are of great utility in the treatment of infantile diarrhoa. A spice-bag, which is a favourite form of such an application in America, is made as follows:-Take a half-ounce each of cloves, allspice, cinnamon, and anise seeds, pounded, but not powdered, in a mortar; put these between two layers of coarse flannel about six inches square, and quilt them in. Soak this for a few minutes in hot spirits (brandy, whiskey, or alcohol) and water, equal parts, and apply it to the abdomen warm, renewing it when it gets cool. In this way we get not only the effects of a poultice, but we also get the sedatire and antiseptic effects of the spices.-N. Y. Med. Record, July 12. 